\title{
INFLUENCE OF CONTROLLED AND UNCONTROLLED CASTING CONDITIONS ON TH-5 EXPLOSIVE DENSITY
}

\author{
Faruk Razić, Zahida Ademović, Miralem Burek \& Jasmin Terzić
}
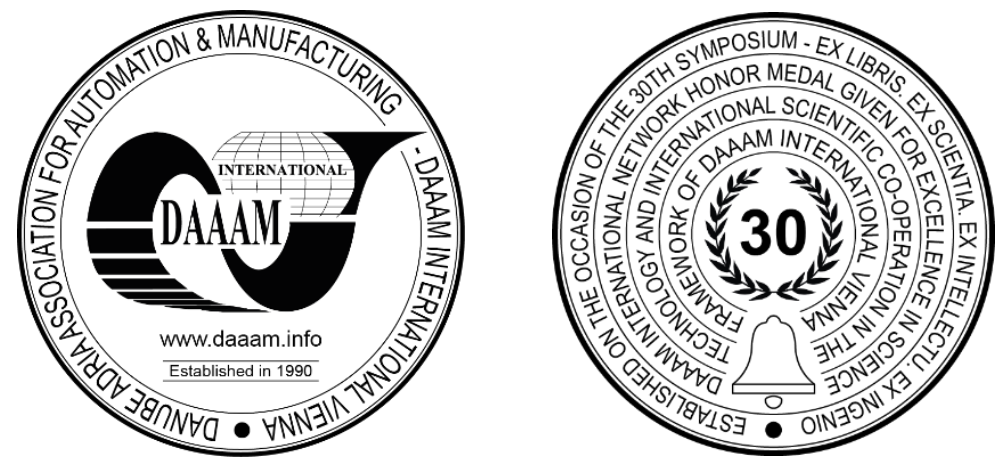

This Publication has to be referred as: Razic, F[aruk]; Ademovic, Z[ahida]; Burek, M[iralem] \& Terzic, J[asmin] (2020). Influence of Controlled and Uncontrolled Casting Conditions on TH-5 Explosive Density, Proceedings of the 31st DAAAM International Symposium, pp.0304-0309, B. Katalinic (Ed.), Published by DAAAM International, ISBN 9783-902734-29-7, ISSN 1726-9679, Vienna, Austria DOI: $10.2507 / 31$ st.daaam.proceedings.042

\begin{abstract}
The process of casting explosives into projectile bodies during ammunition production requires controlled conditions which include preheating of the projectile body, use of special designed funnels for casting, proper mixing of explosive and controlled cooling process. Controlled casting process is required to make high quality castings with high explosive density without presence of lunkers and cracks. The aim of this work is to compare the characteristics of TH5 explosive cast under controlled conditions of different projectiles ranging from $60 \mathrm{~mm}$ mortar projectiles to $155 \mathrm{~mm} \mathrm{HE}$ artillery projectiles. TH5 freely uncontrolled casting is performed without preheating, use of funnel and without mixing and controlled cooling. TH5 is explosive consisted of mainly TNT and 5wt-\% RDX. It is obtained through process of delaboration of non-perspective ammunition through demilitarization process and is used as replacement for pure TNT. Density and cross section of the explosive casts are examined using controlled projectile bodies for both casting processes and comparison of these properties is presented.
\end{abstract}

Keywords: Casting; Explosive; Projectiles; Crystal Structure.

\section{Introduction}

Pure trinitrotoluene (TNT) is one of the most commonly used explosives in military industry. It is convenient for mechanical processing, easy to melt, is very safe for handling and every day operations. All HE projectiles that are filled with TNT are in general prepared by the casting process. However, due to requirements for specific mechanical properties, or in order to change thermal and sensitive properties, pure explosives are very often mixed with other explosives and inert materials [1]. For TNT it is very common to be mixed with hexogen (RDX) forming explosive called Composition B. TNT has negative oxygen balance and the only way to change that property is to mix it with other explosives with positive oxygen balance. Solidification point of TNT has been investigated by many different researchers gaining different solidification points as follows: $80.6^{\circ} \mathrm{C}, 80.65^{\circ} \mathrm{C}, 80.8^{\circ} \mathrm{C}, 80.66^{\circ} \mathrm{C}$. Use of TNT explosive is determined in function of its solidification point. According to US standards, solidification point of TNT for military use is $80.2^{\circ} \mathrm{C}$ and $76.0^{\circ} \mathrm{C}$ for civil purposes. Former Yugoslav and Russian standards define solidification point above $80.2^{\circ} \mathrm{C}$ for use in artillery projectiles and $78.0^{\circ} \mathrm{C}$ for industrial explosives [2] [3]. Density of the castings is highly influential on the final parameters of the explosive. According to [4] [5] difference of $0.01 \mathrm{~g} / \mathrm{cm}^{3}$ in density results in $2 \%$ variation of explosive energy. 
The explosive composition TH-5 consists of the recycled TNT with maximum 5 wt- $\%$ of hexogen (RDX) and inert impurities such as waxes, plasticizers etc. It has been shown that TH- 5 with 0.25 wt- $\%$ content of impurities meets all the requirements, in technological terms, for implementation in ammunition warheads with casting method and it can be used instead of TNT [6].

The explosive charge produced by casting must be homogeneous and have fine-grained structure, without presence of coarse crystals, cracks, cavities and air bubbles. Large crystals of explosive material and cracks of different types can cause explosive charge activation in the barrel. The presence of small air bubbles creates the porosity of the explosive charge and reduces its charge density, which simultaneously reduces the mass, pressure and detonation velocity. Therefore, for the production of high quality explosive cast, the technological casting process must be carried out under controlled conditions

In this work, recycled TH-5 explosive obtained by the delaboration process is cast into HE projectile bodies under controlled and uncontrolled process conditions. The aim of this work is to compare the casting conditions on the quality of the obtained casting.

\section{Case study}

TH-5 that contains 94.95 wt-\% TNT, 4.89 wt-\% RDX, and 0.16 wt-\% impurities (wax and similar substances) was used in this work. Seven different projectiles ranging from $60 \mathrm{~mm}$ mortar bombs to $155 \mathrm{~mm} \mathrm{HE}$ artillery projectiles are used to cast explosive in both controlled and uncontrolled conditions. TH5 cast temperature was $81^{\circ} \mathrm{C}$.

There are many different steps that needs to be performed in order to produce high quality explosive cast such as: heating of the projectile body prior to casting, casting melted explosive using special design funnels (which are different for each type of the projectile) because of the TNT shrinkage during cooling process, proper mixing of the explosive in order to avoid possible lunker formation and controlled cooling of the casted explosive.

Main component of the explosive TH5 is TNT, hence its properties are very similar to TNT. TNT has high rate of shrinkage, which means its volume is decreasing upon cooling process. Therefore, to prevent shrinkage, special funnels are used, which act as reservoir of molten explosive and provide sufficient quantity of explosive for casting process in one or more takes, Fig. 1.
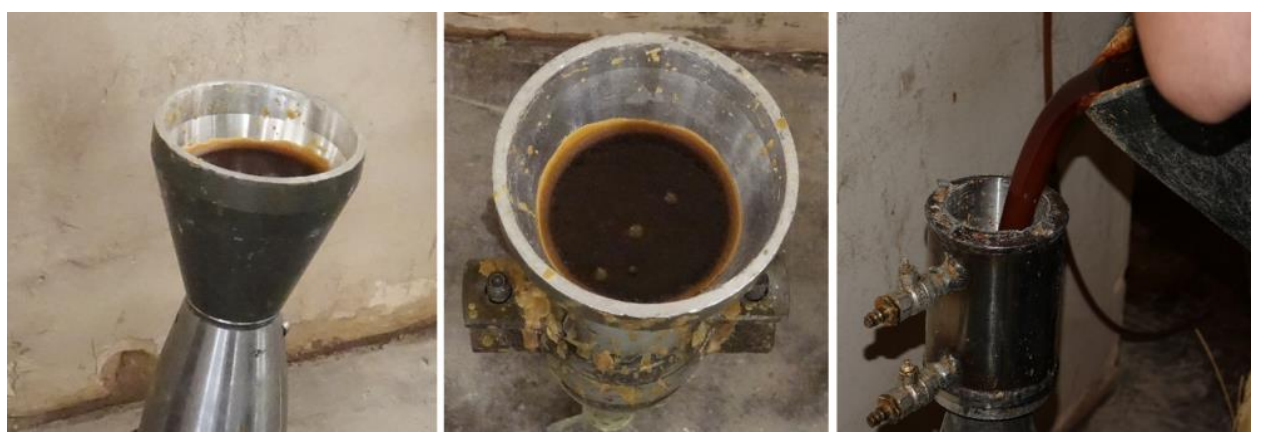

Fig. 1. Funnels for explosive casting

\section{Controlled and uncontrolled casting}

In order to demonstrate importance of controlled casting, TH5 explosive was cast under both controlled and uncontrolled conditions. Some of the controlled cases and their assemblies are presented in Fig. 2. Control case is of the same shape as the HE projectile. It is divided in two sections which can be disassembled in order to remove explosive filling after solidification process is finished.
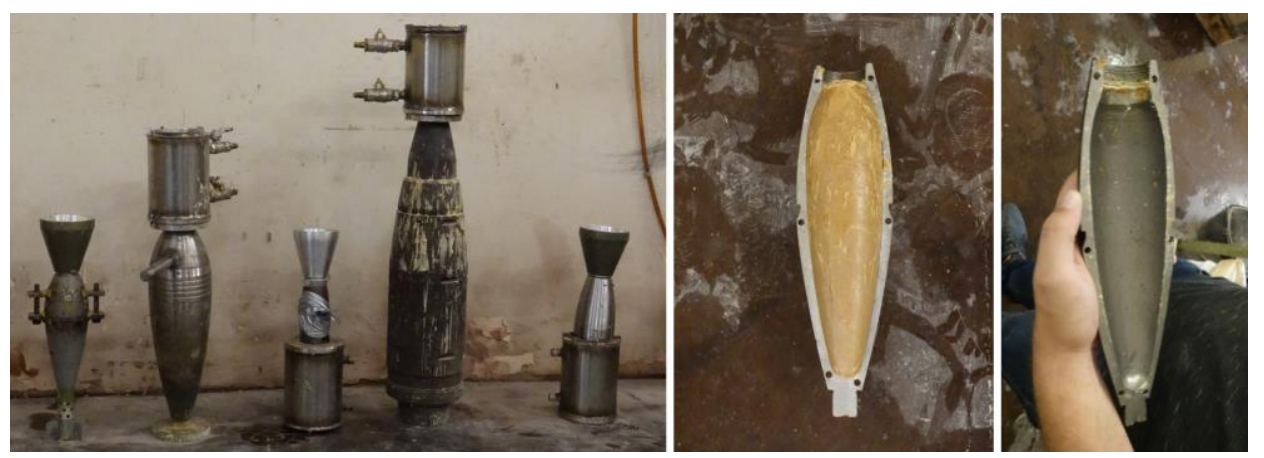

Fig. 2. Control cases for TNT castings 
Controlled conditions assume that all procedures such as heating projectile body to required temperature, hot water circulation through funnel in order to provide molten explosive and prevent solidification on top, mixing of the explosive in projectile bodies to reduce the possibility of lunkers and cracks formation and cooling process are performed.

On the other hand, casting in uncontrolled conditions is performed with the omission of all these controlled procedures, which means projectile bodies are loaded with casted TH5 without water circulation through funnels (to demonstrate natural cooling, shrinkage and solidification on top), without mixing and controlled cooling (to observe lunker and cracks formation during solidification process).

Visual inspection, quality and comparison of the castings are made using cross section of each cast. All seven projectiles have been cut into same pattern presented in Fig. 3. Visual comparison of the casts removed from controlcases of artillery projectile $155 \mathrm{~mm}$, HE, M107 and Mortar projectile $120 \mathrm{~mm}$, HE, M62P3 are presented in Fig. 3.
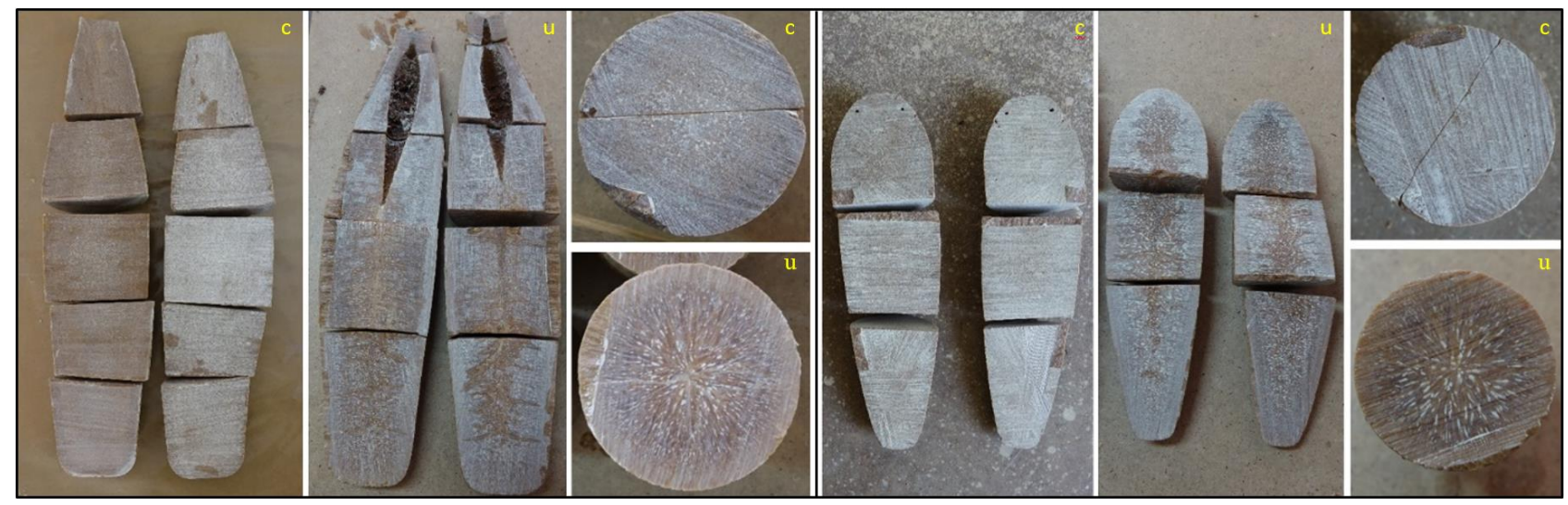

Fig. 3. Comparison of $155 \mathrm{~mm}$ artillery (left) and $120 \mathrm{~mm}$ mortar (right) cast removed from control case - "c" controlled casting, "u" uncontrolled casting

The process of crystallization of explosive charge occurs with the appearance of the first crystals and the number of crystals and their size gradually increases. In order to obtain a uniform cast with a fine-grained structure, the cooling process of the explosive charge should be controlled to ensure the simultaneous formation of as many crystallization centres as possible which also shortens the crystallization process. Faster cooling rate before the appearance of the crystallization centres provide more homogeneous structure of the explosive cast and smaller crystal size.

From Fig. 3 and 4 is evident that the controlled cooling conditions ensure a cast that has a uniform structure along the entire length and cross section of the projectile. Contrary to that, uncontrolled cooling conditions produce a cast with uneven structure where presence of many cracks and lunkers are evident. This defect formation is more pronounced in larger caliber projectiles because the mass of explosives is higher and the time required for cooling is longer. During the cooling of the explosive in the projectile body, solid layers of explosives are formed from the wall of the projectile body towards the central part. The time required for cooling the central part of the projectile is too long and the appearance of many crystallization centres is noticeable in the middle of the samples on the cross section of projectiles produced under uncontrolled casting conditions.

Samples for density inspection are presented in. Fig. 4 For uncontrolled castings of larger projectiles, cavities which are formed due TNT cooling nature process are evident. Most noticeable and largest cavity was present at the highest caliber projectile, $155 \mathrm{~mm}$ M107, with dimensions $240 \mathrm{~mm}$ in length and highest diameter of $30 \mathrm{~mm}$.

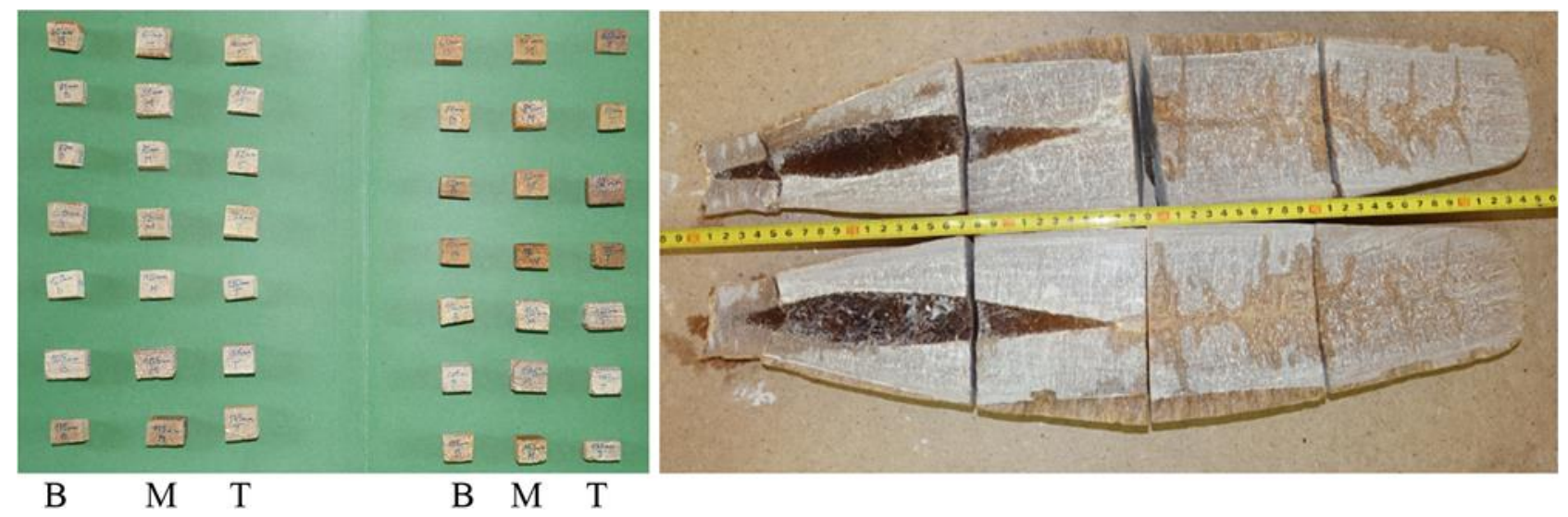

Fig. 4. Samples of all 14 casts for analysis (bottom-B, middle-M, top-T section) and casting cavity 
TNT does not undergo partial decomposition when melted. According to [7] samples of TNT were melted and solidified at least 60 times without significant change in solidification point. Shrinkage due the solidification process is $11 \%$ and crystal density of TNT is $1.654 \mathrm{~g} / \mathrm{cm}^{3}$. Casting conditions have significant influence on density and it is impossible to achieve theoretical crystal density during casting or pressing process. Cast TNT density varies from $1.5-$ $1.6 \mathrm{~g} / \mathrm{cm}^{3}$. Generally speaking, higher densities of $1.63-1.64 \mathrm{~g} / \mathrm{cm}^{3}$ are possible to achieve by pressing of explosive [2]. However, pressed explosives are usually used for detonators and not for main charge of the projectile. Densities achieved by controlled and uncontrolled casting are presented in Table 1. Cast density was determined using Archimedes' principle according to [8] for three sections of the explosive cast: bottom section "B", middle "M" and top section "T".

\begin{tabular}{|c|l|l|c|c|c|}
\hline \multirow{2}{*}{ Projectile } & \multirow{2}{*}{ Casting Conditions } & \multirow{2}{*}{ Explosive Mass [kg] } & \multicolumn{3}{|c|}{ Density [g/cm } \\
\cline { 4 - 6 } & & & B & M & T \\
\hline Mortar projectile $60 \mathrm{~mm}$, & Controlled & 0.370 & 1.580 & 1.547 & 1.567 \\
HE, M90 & Uncontrolled & 0.364 & 1.572 & 1.551 & 1.527 \\
\hline Mortar projectile 81 mm, & Controlled & 0.826 & 1.561 & 1.526 & 1.498 \\
HE, M17LR & Uncontrolled & 0.835 & 1.546 & 1.501 & 1.452 \\
\hline Mortar projectile 82 mm, & Controlled & 0.682 & 1.592 & 1.573 & 1.545 \\
HE, M74 & Uncontrolled & 0.669 & 1.573 & 1.511 & 1.436 \\
\hline Mortar projectile 120 mm, & Controlled & 3.039 & 1.578 & 1.552 & 1.539 \\
HE, M15LR & Uncontrolled & 2.960 & 1.591 & 1.496 & 1.485 \\
\hline Mortar projectile 120 mm, & Controlled & 2.450 & 1.572 & 1.552 & 1.525 \\
HE, M62P3 & Uncontrolled & 2.430 & 1.561 & 1.509 & 1.403 \\
\hline Artillery projectile 105 mm, & Controlled & 2.250 & 1.582 & 1.563 & 1.549 \\
HE, M1 & Uncontrolled & 2.130 & 1.594 & 1.519 & 1.491 \\
\hline Artillery projectile 155 mm, & Controlled & 6.700 & 1.608 & 1.554 & 1.556 \\
HE, M107 & Uncontrolled & 6.650 & 1.543 & 1.555 & 1.521 \\
\hline
\end{tabular}

Table 1. Densities achieved by casting of TH5

For smaller calibar HE ammunition such as 60, 81 and $82 \mathrm{~mm}$ mortar projectiles, beside mixing of explosive during cooling process and use of funnels for casting, other actions such as projectile body heating, funnel heating and controlled cooling are not performed during controlled casting. Table 1 and Fig 5. clearly show influence of process conditions of casting on explosive density.
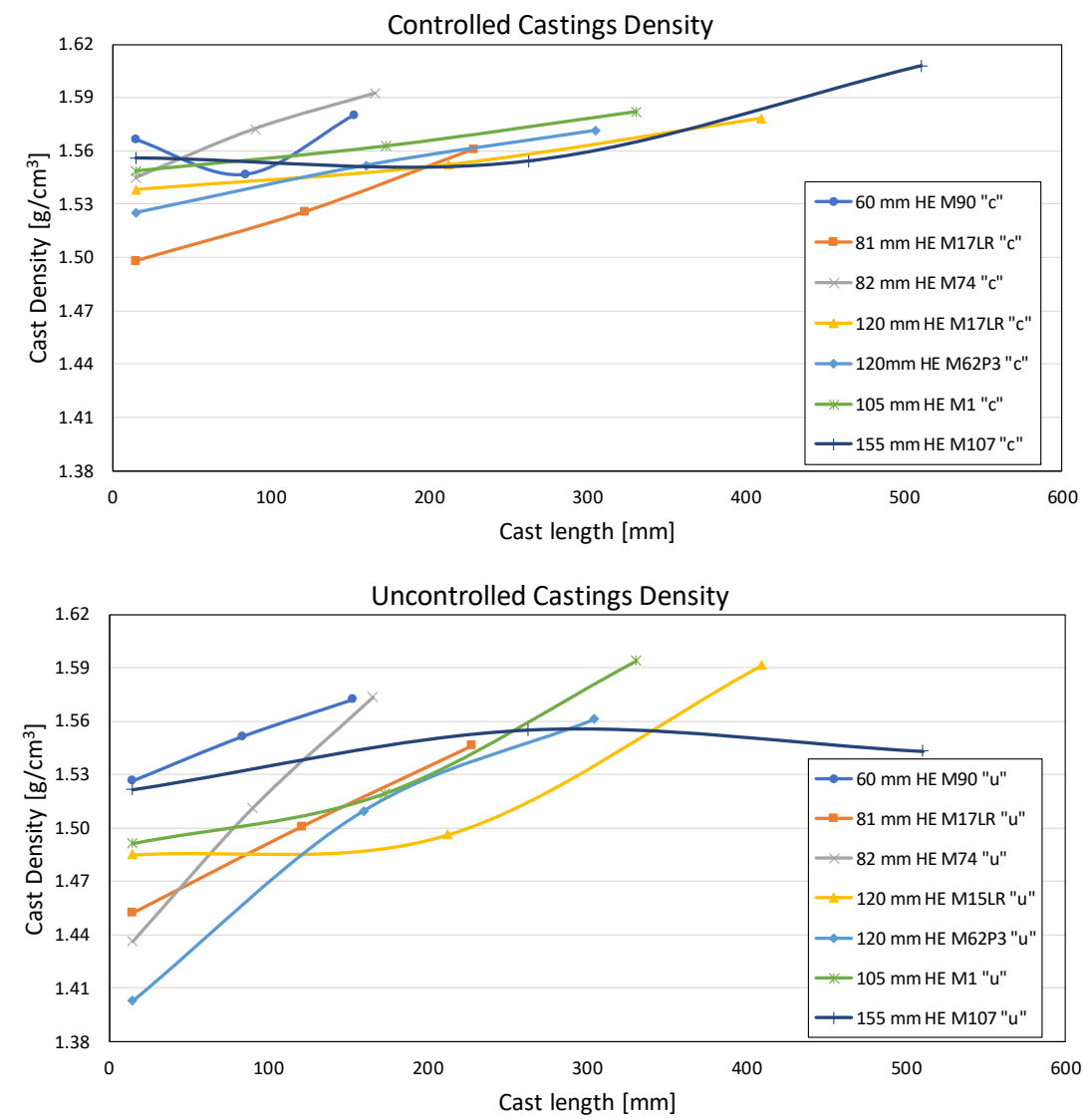

Fig. 5. Densities of both, controlled and uncontrolled castings of seven different projectiles 
Casting under controlled conditions mainly produce explosive cast with higher densities in the bottom, middle and top part of the castings for the same caliber. The exceptions are $120 \mathrm{~mm}$ M15LR mortar with density at the bottom $1 \%$ higher for uncontrolled casting and $60 \mathrm{~mm}$ M90 mortar with density in the middle part which was $0.25 \%$ higher for uncontrolled casting. All measured densities are ranging from $1.498 \mathrm{~g} / \mathrm{cm}^{3}$ for lower and $1.608 \mathrm{~g} / \mathrm{cm}^{3}$ for highest density for controlled casting. For uncontrolled casting, lowest density achieved was $1.403 \mathrm{~g} / \mathrm{cm}^{3}$ and highest $1.594 \mathrm{~g} / \mathrm{cm}^{3}$. This change of density will also affect fragment velocity and moment of fracture of the projectile metal body [9] [10].

Of course, for lower density explosive casting it is expected for detonation velocity and pressure to be lower as well. In order to compare these values, EXPLO5 software was used [11]. Comparison has been made for two projectiles, artillery projectile $155 \mathrm{~mm}$, HE, M107 and mortar projectile $120 \mathrm{~mm}$, HE, M62P3. Highest densities for both $155 \mathrm{~mm}$ and $120 \mathrm{~mm}$ projectiles were for controlled conditions at the bottom as it was expected, $1.608 \mathrm{~g} / \mathrm{cm}^{3}$ and $1.572 \mathrm{~g} / \mathrm{cm}^{3}$ respectively. Detonation pressure and velocity were determined for both, controlled and uncontrolled conditions for mean densities. Since TH5 is explosive which consists of mainly TNT and 5wt-\% RDX, composition of 95\% TNT and 5\% RDX was chosen for this analysis.

\begin{tabular}{|c|c|c|c|c|}
\hline & \multicolumn{2}{|c|}{ Projectile 155 mm HE, M107 } & \multicolumn{2}{|c|}{ Projectile $120 \mathrm{~mm}$ HE, M62P3 } \\
\hline Composition & \multicolumn{4}{|c|}{$95 \% \mathrm{TNT}-5 \% \mathrm{RDX}$} \\
\hline Casting conditions & Controlled & Uncontrolled & Controlled & Uncontrolled \\
\hline Density & $1.572 \quad\left(\mathrm{~g} / \mathrm{cm}^{3}\right)$ & $\left(\mathrm{g} / \mathrm{cm}^{3}\right)$ & $1.555 \quad\left(\mathrm{~g} / \mathrm{cm}^{3}\right)$ & $\left(\mathrm{g} / \mathrm{cm}^{3}\right)$ \\
\hline Detonation velocity & $6947.5 \quad(\mathrm{~m} / \mathrm{s})$ & $6881.7 \quad(\mathrm{~m} / \mathrm{s})$ & $6901.8 \quad(\mathrm{~m} / \mathrm{s})$ & $6675.2(\mathrm{~m} / \mathrm{s})$ \\
\hline Detonation pressure & 184.216 (kbar) & 177.834 (kbar) & 179.812 (kbar) & 163.227 (kbar) \\
\hline Temperature & $3798.7 \quad(\mathrm{~K})$ & $3808.5 \quad(\mathrm{~K})$ & $3805.5 \quad(\mathrm{~K})$ & $3790.7 \quad(\mathrm{~K})$ \\
\hline Oxygen Balance & \multicolumn{4}{|c|}{$-71.3426(\%)$} \\
\hline Reactant brutto formula & \multicolumn{4}{|c|}{$\mathrm{C}(6.796) \mathrm{H}(5.051) \mathrm{N}(3.153) \mathrm{O}(6.0)$} \\
\hline Energy of formation (at $298.15 \mathrm{~K}$ ) & \multicolumn{4}{|c|}{$-154.805(\mathrm{~kJ} / \mathrm{kg})$} \\
\hline Enthalpy of formation (at $298.15 \mathrm{~K}$ ) & \multicolumn{4}{|c|}{$-232.402(\mathrm{~kJ} / \mathrm{kg})$} \\
\hline
\end{tabular}

Table 2. Detonation pressure, velocity and other detonation parameters of two castings with different densities

\section{Conclusion}

This work presents the influence of casting process control on the structure and quality of explosive cast. Casting under uncontrolled process conditions leads to the formation of defects in the casting that affects the quality of the explosive casting and the final projectile. These defects can cause malfunctions in the projectile which can lead to catastrophic consequences when using the projectile. Due to the formation of cracks and lunkers, casting under uncontrolled condition also produces cast with lower densities, which in turns reduces the mass, pressure and detonation velocity of the projectile.

For further research on this subject, authors suggest static testing of the projectile efficiency in ARENA test, where spatial distribution of fragments is tested and lethal radius of projectile will be defined, and so called PIT test where mass distribution of fragments is tested. These tests will provide necessary data for evaluation of the projectile and influence of the casting conditions on mass and spatial distribution of fragments.

\section{Acknowledgments}

The authors are thankful to "Pretis d.d." Vogosca for providing their test facility, equipment and staff for preparation and explosive sampling.

\section{References}

[1] Cooper, P.W. (1997). Explosives Engineering, John Willey \& Sons, ISBN 0-471-18636-8, New York

[2] Maksimovic, P.V. (1985). Explosive Materials Technology [Tehnologija Eksplozivnih Materija], Military Publishing Bureau, Belgrade

[3] Maksimovic, P.V. (1972). Explosive Materials [Eksplozivne Materije], Military Publishing Bureau, Belgrade

[4] Murphy, M.J. (1989). The effects of gradients in HMX/TNT content and porosity on shaped charge jet characteristics, Proceedings of the 11th Symposium (International) on Ballistics, UCRL-99492, CONF-890585-2 Brussels

[5] Kumar, S.A. \& Rao, D.V. (2014). Modeling of cooling and solidification of TNT based cast high explosive charges, Defence Science Journal, Vol. 64, No. 4, 2014, pp. 339-343., ISSN 0011-748X, DOI: 10.14429/dsj.64.4673

[6] Bobic, N., Terzic, S., Dimic, M., Simic, D., Nikolic, J. \& Drmanic, S. (2016). Verification of the explosive quality of TH-5, Propellants, Explosives and Pyrotechnics, Vol. 41, No. 1, 2016, pp. 120-125., ISSN 1521-4087, DOI: 10.1002/prep.201500012

[7] Department of the army technical manual. (1984). Explosive Materials, U.S. Government Printing Office: 1995388-421/140013, TM 9-1300-214, Washington, DC 
[8] North Atlantic Treaty Organization. (2003). Manual of data requirements and tests for the qualification of explosive materials for military use, AOP-7 (Edition 2), NATO standardization agency (NSA)

[9] Zecevic, B.; Terzic, J.; Razic, F. \& Serdarevic-Kadic, S. (2015). Lethal influence factors of natural and preformed fragmentation projectiles, In: DAAAM International Scientific Book, Branko Katalinic (Ed.), pp. 219-234, Published by DAAAM International, ISBN 978-3-902734-05-1, Vienna, Austria, DOI: 10.2507/daaam.scibook.2015.20

[10] Zecevic, B.; Terzic, J. \& Catovic, A. (2004). Influence of warhead design on natural fragmentation performances, Proceedings of the 15th DAAAM International Symposium, Intelligent Manufacturing \& Automation: Globalization - Technology - Men - Nature, Vienna, ISSN 1726-9679, ISBN 3-901509-42-9, Katalinic, B. (Ed.), Published by DAAAM International, Vienna

[11] Suceska, M. (2008). Explo 5 Software, Version 5.03/Edition 4/2008 